\title{
Notas para una memoria histórica sobre las infancias producidas por el conflicto armado en Colombia
}

\author{
Notes for a historical report on the childhoods caused by the armed conflict in \\ Colombia
}

Camilo Bácares Jara comalarulfo@hotmail.com

Universidad del País Vasco, España

Recepción: 09 Octubre 2019

Aprobación: 20 Junio 2020

Publicación: 01 Diciembre 2020

Cita sugerida: Bácares Jara, C. (2020). Notas para una memoria histórica sobre las infancias producidas por el conflicto armado en Colombia. Aletheia, 11(21), e073. https://doi.org/10.24215/18533701e073

\begin{abstract}
Resumen: La infancia es un hecho social y por este principio no se reduce a una única expresión. En Colombia, las investigaciones de la memoria histórica han omitido esta concepción sociológica al resumir la interacción de la guerra y la infancia al estudio del reclutamiento de menores de edad. Ante esto, este artículo invita a construir una memoria histórica de las infancias olvidadas y desprovistas de existencia en la narración del conflicto armado. Para tal fin, propone empezar por cuatro infancias (la desplazada, la masacrada, la desaparecida y la violentada sexualmente), tomando en cuenta algunas herramientas metodológicas e interpretativas para abordarlas.
\end{abstract}

Palabras clave: Memoria colectiva, Infancia, Conflicto armado, Colombia.

Abstract: Childhood is a social fact and by this principle it is not reduced to a single expression. In Colombia, historical memory research has omitted this sociological conception by summarizing the interaction of war and childhood to the study of the recruitment of minors. Given this, this article invites to build a historical memory of forgotten childhoods and devoid of existence in the narration of the armed conflict. To this end, he proposes to start with four childhoods (the displaced, the massacred, the disappeared and the sexually violated), taking into account some methodological and interpretative tools to address them.

Keywords: Collective memory, Childhood, Armed conflicts, Colombia.

-;Oiga, mayor, aqui hay uno que dice que no quiere matar a niños! -¿Quién es el pendejo que ha dicho eso?- respondió enojado el mayor, que caminaba dando grandes zancadas.

Éste no dudó en hacer lo que cualquier militar habria hecho en su situación: demostrar su liderazgo. Avanzó hacia el grupo de niños, cogió a un crio, lo lanzó al aire y lo empaló mientras caía. Aquello puso fin a la discusión (Danner, 2016, p.88)

Cuántas veces nos hemos preguntado: pero, ¿por qué matan a los niños? Para eso, para no dejar ni la semilla del bando contrario.

(Guzmán Campos, Fals Borda y Umaña Luna, 2014, p. 247) 


\section{INTRODUCCIÓN ${ }^{1}$}

Como bien se sabe, la memoria histórica referida a dotar de inteligibilidad y significación a los episodios de violencia política en América Latina explosionó a finales de los años ochenta con el fin de las dictaduras militares y el tránsito en la región hacia gobiernos civiles elegidos en las urnas (Jelin, 2012). En ese transcurrir surgieron las primeras comisiones de la verdad para estudiar qué, cómo y por qué se configuraron los regímenes castrenses, las guerras y las víctimas producidas por su accionar en países como Argentina, Chile, Guatemala o El Salvador. Particularmente en Colombia, la empresa de la memoria histórica se podría rastrear un poco antes con los incipientes estudios que se desarrollaron en los años cincuenta (Jaramillo Marín, 2014) y que en la actualidad se masificarían con la producción investigativa del Grupo de Memoria Histórica de la Comisión Nacional de Reparación y Reconciliación, la del Centro Nacional de Memoria Histórica y la que está realizando la Comisión para el Esclarecimiento de la Verdad, la Convivencia y la No Repetición por mandato del acuerdo de paz firmado entre el Estado colombiano y las Farc-Ep en La Habana (República de Colombia, 2017).

Con esto en mente, no es descabellado afirmar que a la fecha existe un acumulado gigantesco de páginas que exploran la memoria histórica y que han visibilizando a la mayoría de grupos poblacionales alcanzados por las violencias estatales, paraestatales e insurgentes. A pesar de ello, la categoría de la infancia y su multiplicidad ha sido dejada de lado en este gran cúmulo de investigaciones. Lo que en sí resulta una contradicción y una gran paradoja, dado que los estudios de la memoria y los testimonios que se recolectan para su organización se fundan en "un modo alternativo de narrar la historia, en relación con el discurso monológico de la historiografía del poder, ya que es más plural y busca el respeto de otras identidades" (Blair, 2008, p. 88).

En efecto, -casi en un contrasentido- esta indagación de historias alternativas, silenciadas y excluidas de las narraciones oficiales derivó en que los Niños, Niñas y Adolescentes (NNA) fueran reinvisibilizados o colocados en un plano totalmente secundario en la bibliografía de la memoria concatenada a la violencia política. Por ejemplo, la evidencia comparada y los antecedentes de las comisiones de la verdad en el mundo demuestran que los padecimientos y las voces de los NNA se han integrado y analizado con menor atención en sus informes finales respecto de otras poblaciones (Bácares, 2019), exceptuando claro, algunos experiencias donde tuvieron un poco más de espacio como en la de Guatemala, Perú, Timor del Este, Paraguay y Sierra Leona (Comisión para el Esclarecimiento Histórico; 1999; Comisión de la Verdad y Reconciliación, 2003; Comisión Verdad y Justicia, 2008; Parmar, Roseman, Siegrist, y Sowa, 2010; Commission for Reception, Truth and Reconciliation. The Timor-Leste, 2013). ${ }^{2}$

En lo que concierne a Colombia, la tendencia recién narrada se replicaría a cabalidad. Entre tantas razones que la explican, el escaso hábito académico de trabajar la infancia, la memoria y la violencia política en el país (Cárdenas, 2018; Jara Gómez, 2017; Pachón Castrillón, 2016; Uribe Alarcón, 2015; Torres, E., Cárdenas, Y. y Pertuz, C. (2018), ${ }^{3}$ o la desconfianza en los NNA como testigos (CNMH, 2018a; Vallejo Franco, 2018), puede que hayan servido para justificar y perpetuar este ostracismo. Aunque, a modo particular, el mayor sostén de este aplazamiento se cimienta en la reducción de las infancias en la guerra a una sola cara o expresión. Sin lugar a dudas, en el ámbito nacional los escritos que se interesaron por los NNA en el entorno de la guerra asimilarían a la infancia en términos singulares, es decir, comprimiéndola y homogeneizándola a la categoría Child Soldiers impuesta por Naciones Unidas (Machel, 1996; Unicef, 2009), o en su adaptación local e institucional, a la de los NNA desvinculados de los grupos armados al margen de la ley.

Decisión y curso que a la luz de la sociología de la infancia implica una lectura parcial y limitada del fenómeno, puesto que la infancia es "una realidad socialmente construida, que como tal presenta variaciones histórica y culturalmente determinadas por el conjunto de mandatos, pautas y normas de conducta que se aparejan al modo de ser niño en un momento concreto" (Gaitán, 2006, p. 10). Mejor dicho, si la infancia se caracteriza por ser una experiencia y un estado fomentado por ideas, prácticas, relaciones sociales e instituciones que determinan que la vivencia de la niñez sea múltiple, diferente y diversa, el haberla limitado 
a un punto de vista analítico es un error conceptual (Sánchez Parga, 2004). En especial, cuando al devenir en una construcción, la guerra como un suceso social no es ajena a elaborarla también, decidiendo para los NNA roles, interpretaciones, sentidos, imágenes y destinos tan disímiles y deslocalizados (Alexiévich, 2016; Cussiánovich, 2004; Egaña, 2009; Gil y García, 2009; Rosen, 2005, 2015; Winterberg y Winterberg, 2011, 2015), como torturar o ser torturados en la Nicaragua somocista (Mejía Duque, 1982), ser utilizados para moralizar a los soldados en la II Guerra Mundial mediante cartas (Sierra, 2009, p.110), o morir inermes como se relata a continuación- en los bombardeos acaecidos durante la guerra civil española en el País Vasco:

\begin{abstract}
El primer bombardeo aéreo de la historia en suelo vasco se produjo en Otxandio, el miércoles 22 de julio de 1936, con el resultado de 84 muertos, más de la mitad niños, entre ellos cinco de una misma familia, los Garcés: Pedro, Teodoro, Juan Manuel, Mertxe y José Mari. Una avioneta descendió paulatinamente para situarse a escasa altura, hasta el extremo de que todos los niños arremolinados en la plaza vieron a su piloto saludar con un pañuelo. Al sobrevolar la plaza, la avioneta arrojó unos objetos que los niños corrieron a recoger pensando que se trataba de algún tipo de regalo. ¡Qué lejos estaban de la realidad! Los objetos lanzados, con la mano y no con algún artilugio propio de un bombardero, no eran sino bombas de tres o cuatro kilogramos de peso (Egaña, 2009, p. 82).
\end{abstract}

De este modo, el posicionamiento del reclutamiento ilícito de los NNA como la noción imperante conllevaría a simplificar el encuentro de la guerra con la niñez, al privilegiar a una infancia de las tantas existentes, en lo que atañe a la exploración de su invención y presencia en el conflicto armado. Así lo prueban, por un lado, las aproximadamente 177 investigaciones producidas en Colombia entre 2001 y 2017 que se concentran en este tipo de NNA (Bácares, 2017), además con un idéntico corte analítico: que es víctima, vulnerable, maleable, etc.; en parangón de otras entradas alternativas y afines a otras tesis que reconocen que los NNA pueden tener una vinculación generacional con las confrontaciones o perseguir fines altruistas (Molano, 1999, 2017; Medina Gallego, 1996; Rodríguez Bautista y García, 2017). Por otra parte, vale anotar que los esfuerzos, logros y hallazgos del Centro Nacional de Memoria Histórica conforme a las infancias, contrariamente a lo postulado por Sánchez (2017) no alcanzarían para percibir la situación de la niñez en el conflicto armado en "sus verdaderas dimensiones" (p. 111). Lo que hasta ahora prepondera en su haber son varias pinceladas de algunas infancias que ha ocasionado el conflicto armado, donde el NNA reclutado sigue teniendo una vigencia importante, al igual que la niña por el enfoque de género y todo lo referido a las huellas psíquicas y emocionales de la guerra en los NNA por la preponderancia del enfoque psicosocial (CNMH, 2009, 2010, 2011a, 2011b, 2011c,2012, 2013, 2014, 2016, 2017, 2018b). Pero, a diferencia de las mujeres, de los sindicalistas, del colectivo LGTB, de los campesinos, o de los adultos en general, los NNA desde este ente siguen careciendo de una publicación especializada y capaz de dar cuenta de las afectaciones y de las infancias que la guerra colombiana, sociológicamente hablando, creó, permitió y puso en marcha.

De ahí que, la preeminencia del reclutamiento ilícito como el gran contenedor aparente de los NNA en el conflicto armado haya puesto en un segundo renglón o en una postergación investigativa, comunicacional, judicial, política y académica a otras infancias que lo bélico delineó y construyó a sus anchas. Ciertamente, son innumerables las infancias y las memorias de las mismas que se encuentran, siguiendo el concepto de Blair (2002), atrapadas en las hostilidades. En concreto, existe un montón de información, de fuentes documentales y de subjetividades perdidas a la espera de investigaciones diversificadas para conocer las elaboraciones e ideas que condujeron a que a los NNA se les masacrara, desapareciera, torturara, secuestrara, robara su identidad y asesinara -entre tantas más producciones sociales del conflicto armado colombiano-, como ya a cuenta gotas lo han intentado otras rememoraciones que abordan la violencia política y la infancia en el mundo (Comisión Verdad y Justicia, 2008; Melvern, 2007; Ocampo Saravia, 2013). Asimismo, en esta búsqueda se hace necesario explorar otras expresiones de la infancia que la guerra produjo como la de los embarazos coaccionados por los combatientes guerrilleros, paramilitares y de las mismas fuerzas armadas de las que no hay más que unas pocas cuartillas publicadas o sobre la de los hijos de los guerrilleros que durante generaciones nacieron en las selvas de Colombia (Ila, Ávila, Arias, Núñez y Caicedo, 2009; Tovar Rojas, 2006; Coalico, 2014; Oxfam y Casa de la Mujer, 2010). 
Por lo anterior, el texto entre manos plantea un somero repaso y análisis de las infancias más aplazadas y descartadas a lo largo de la memoria histórica oficial y alternativa, con el ánimo de exponer esta situación y de paso invitar a quienes se interesen por esta cuestión a investigar a estas infancias apresadas en el conflicto armado colombiano. Para ello, primero, se tratará a la infancia desplazada y su riqueza de fuentes para estudiarse y conformarse un cuadro general y meticuloso de su configuración. En segundo lugar, se repasará la noción de las masacres y las hipotéticas razones que han favorecido su encuentro con los NNA. En tercer lugar, se trabajará el fenómeno de la desaparición forzada y las dificultades metodológicas que arrastra para ampliarse en torno a la infancia. Finalmente, se examinarán los retos y desafíos que encara una memoria histórica de la niña en el conflicto armado nacional para seguir con detalle la violencia sexual y en ese trance resaltar sus estrategias de resistencia y con ello intentar no encasillarla unidimensionalmente como una mera víctima.

\section{EL DESPLAZAMIENTO FORZADO EN LOS NNA}

En teoría, la historización de la infancia desplazada forzadamente podría considerarse como una de las que más camino tiene recorrido y de las que posee mayores chances de ampliarse en el país. La acumulación de datos explicativos sobre los impactos de esta problemática en los NNA, muy cercanos en número a los del tópico predominante del alistamiento infanto-adolescente, pueden servir precisamente de soportes para la edificación de una memoria histórica autónoma y propia de los NNA desplazados en la guerra colombiana. Verbigracia, por las investigaciones de corte cuantitativo se tiene conocimiento de que la vivencia del desplazamiento forzado es la madre de muchas expresiones violentas en contra de los NNA y que a la par esta es provocada por otras acciones guerreristas en el desenvolvimiento del conflicto armado: de hecho, se tiene conocimiento de que los NNA reclutados por las guerrillas y por el paramilitarismo alcanzaron a desplazarse por lo menos tres veces en sus vidas antes del enganche al actor armado (Bácares, 2014); y que, en muchos casos, el desplazamiento se convirtió en forzado por la materialización de masacres, asesinatos o por la desaparición forzada de los miembros de un hogar (Rojas Rodríguez y Romero Silva, 2000).

En cierto modo, el desplazamiento forzado de los NNA tiene una interdependencia con otras coerciones para vehiculizarse y esto hace que su elaboración histórica sea muy rica y en un agregado, amplia y polifónica a causa de su magnitud en este grupo poblacional. Piénsese que, si el Registro Único de Víctimas (RUV), estableció que al corte de septiembre de 2018 el total de la población desplazada era de 7.434.999 personas, que en lo que respecta a los NNA, un conjunto de 2.290.452 desplazados correspondió a menores de edad al momento de que ocurrieran los hechos declarados (Gobierno de Colombia y Unidad para las Víctimas, 5 octubre 2018). ${ }^{4}$ De tal forma, los proyectos a realizarse en este tópico infanto-adolescente tienen por delante una cantidad interminable de relatos y testimonios por recopilar, y de averiguaciones por encontrar en los archivos estatales y no gubernamentales que pueden servir de fuentes para conocer, entre muchas cosas si los NNA únicamente derivaron en objetos de protección de sus familias, o si en otros casos, se desplazaron autónomamente y bajo su propio riesgo como ocurrió en la última de las guerras civiles del siglo XIX; o en otro tono ¿̇en qué ha consistido diferencialmente la experiencia del desplazamiento para un NNA afrodescendiente, uno campesino o uno indígena, según sus provocadores y los servicios institucionales y las violencias encontradas en los nuevos lugares de residencia?

Adicionalmente, la infancia desplazada brinda como pocas infancias engendradas en los ires y venires del conflicto armado una oportunidad metodológica mayor para entender su manufactura. Sucede -como se verá en los siguientes acápites- que en contraste con la mayoría de otras infancias suscitadas por la guerra, la del NNA desplazado está mediada por una racionalidad más abocada a producir en ellos y en sus redes familiares la imposibilidad de una negociación o de una escogencia para sobrellevar la vida y permanecer en los contextos de donde eran oriundos que la del objetivo literal de la eliminación. Por esto, los NNA desplazados se pueden asumir bajo el planteamiento de testigos sobrevivientes (Blair, 2008), que quizás, ya han adelantado una 
reflexión sobre su experiencia en relatos, diarios, cartas y escritos autobiográficos donde han consignado sus intimidades, puntos de vista, sensaciones, lecturas, y explicaciones complementarias de lo dicho o no, sobre ellos de cara al conflicto armado. Así pues, el estudio de esta infancia podría sostenerse -como es lógico- en testimonios tomados a sus víctimas y en -un plus innovador- en la recopilación de los textos de su autoría que hubiesen puesto en primera persona las vivencias de los NNA desplazados. Al implementarse este enfoque, se les reconocería como testimoniantes directos y se validaría a sus redacciones como fuentes históricas para entender el desplazamiento y el exilio forzado desde una óptica infantil como se ha hecho en otras latitudes con documentos como el de Filipa Filipović en la guerra de Bosnia (1994), el de Conxita Simarro en la guerra civil española (2015), el de Mariana Masera en la dictadura argentina (Casal, 2017), o con otros tantos que contienen correspondencia y diarios de NNA sitiados y desplazados por un lista interminable de beligerancias (Alonso Carballes, 1998; Cenarro, 2009; Filipović y Challenger, 2007; Zafra, Crego y Heredia, 1989).

Vale agregar, en pro de hallar nuevas variantes y ramas de lo que ha sucedido con los NNA desplazados en el país, que en Colombia el desplazamiento se fraguó también para el despojo de tierras o para componer una contrarreforma agraria, que sin tenerlos en mente los afectó. Se estima que "existen más de 8,3 millones de hectáreas (358.937 predios) despojadas o abandonadas por la fuerza” (CNMH, 2013, p. 76), de las cuales muchas les pertenecen a NNA que quedaron en la orfandad tras la resolución de los hechos violentos que activaron el desplazamiento. Por tal razón, a los interesados en reflexionar sobre esta infancia les puede resultar útil y prioritario recopilar los procesos de reconocimiento y de reparación de los NNA como titulares de las propiedades arrebatadas, que mediante sentencias judiciales han empezado a surgir (Correa, 2015). La primera de ellas tardó más de 15 años en emitirse, para que puntualmente, las trillizas Daniela, Dania y Dalia Castillo Legarda, pudieran recuperar a sus diecisiete años de edad las 25 hectáreas de tierra que en su momento pertenecieron a sus padres hasta 1998 cuando fueron asesinados por varios escuadrones paramilitares (Rodríguez Rojas, 2017). En consonancia, investigando en archivos notariales, judiciales, etc., y cruzando la información obtenida con las zonas más agobiadas por la coacción amada para la expropiación de tierras, en todo este entramado de la infancia desplazada, se puede abrir un nuevo capítulo que de luces sobre qué sucedió con los NNA huérfanos despojados de su derecho a la herencia en el marco del conflicto armado colombiano.

\section{LAS MASACRES Y LOS NNA}

Ni los lugares comunes que asocian y encierran a los NNA a nivel emocional y discursivo en la inocencia, los derechos, la fragilidad o la incapacidad, resultaron suficientes para que se les protegiera de la práctica de la masacre en lo corrido del siglo XX. Por medio de ella, una inédita infancia con significados precisos saldría a la luz en el campo de la guerra y sorpresivamente quedaría a su par -posiblemente por la violación de esos principios donde la victimización fue mayor- escondida de las narraciones históricas y desprovista de esfuerzos por la recuperación de las voces de los sobrevivientes, de los NNA circundantes a su aplicación o de los móviles que llevaron a los perpetradores a convertir en diana militar a los NNA no combatientes o a los acusados de participar de alguna actividad armada e insurrecta.

Por supuesto, ya es de conocimiento público que en varios conflictos armados como en el de El Salvador, a los NNA se les dedicaron masacres específicas donde se les disparaba, empalaba y degollaba en las operaciones contrasubversivas de los años ochenta (Danner, 2016); o que en Vietnam, el ejército estadounidense -en la famosa operación Search and Destroy - mató a mansalva en 1968 a decenas de bebés y NNA a culatazos, a tiros y atravesándolos con bayonetas (Hernández, 2009); empero, la disponibilidad de estas memorias corresponden a hechos que en su debido momento terminaron siendo inocultables a la opinión pública gracias a la publicación de textos en los que los sufrimientos y efectos de las masacres en los NNA se tornaron en datos secundarios o llanamente en demostrativos de la brutalidad y ensañamiento de los victimarios. Como tal, lo poco que se sabe ha estado lejos de provenir de una vertiente especializada en estudiar qué pasó 
con los NNA en las masacres, de indagar cuál ha sido su papel en las mismas, de acertar por qué se les ha incluido en ellas como víctimas o ejecutores, o a razón de qué en otras ocasiones a los NNA se les mutiló como una forma de castigo en matanzas donde a los adultos sí se les eliminó:

El 19 de agosto de 1993, una columna de unos 200 elementos del PCP-SL atacó ocho campamentos de colonos en la provincia de Satipo, en Junín. En esa incursión asesinaron a más de 55 personas, entre nativos y colonos, y cortaron las orejas a 14 niños (Comisión de la Verdad y Reconciliación, 2003, p. 610).

Particularmente, en Colombia, tantear unos antecedentes relacionados con el binomio masacres y NNA es bastante difícil. Tal vez, sólo acudiendo a los estudios antropológicos e históricos de la llamada época de La violencia es posible encontrar algunos de los primeros rastros de los NNA a manera de víctimas. Partamos de que, el asesinato de NNA en ese lapso era una práctica acostumbrada para censurar o ponerle un límite a la descendencia de los antagonistas políticos y militares echando mano de un despliegue de cortes en el cuerpo e inclusive de ataques a las madres gestantes arrancándoles los fetos y poniendo gallos en su lugar (Guzmán Campos, Fals Borda y Umaña Luna, 2014, p. 248). Por este motivo, en varias de las páginas de Uribe Alarcón (2004) aparecen unas contadas menciones de masacres donde a los NNA por ser hijos de personas identificadas con una identidad política opuesta a la de sus victimarios se les impuso la supresión física en ocasión de estos asesinatos masivos:

Entre las masacres "chulavitas" que más recuerdan los campesinos tolimenses se puede mencionar la de El Topacio, escasamente reseñada por los autores del libro La violencia en Colombia. Esta tuvo lugar en 1952 y en ella murieron asesinados cerca de ochenta campesinos liberales que fueron amarrados por el cuello y despedazados a machete. Varios niños fueron arrojados a la caldera de un trapiche [....] Otra masacre ocurrió en un sector del municipio de Santa Isabel, en el Tolima, de mayorías conservadoras. Durante esta fueron asesinados ochenta y dos varones, una mujer y cuatro niños sin que se conozcan detalles de la misma (Uribe Alarcón, 2004, p.53).

Pasado este período, en lo sucesivo del conflicto armado contemporáneo a los NNA se le seguiría masacrando. Los reportes oficiales señalan que 405 NNA fueron asesinados en alguna de las 1.982 masacres que se cometieron en la línea de tiempo 1980-2012 (CNMH, 2013). En relación a esto: ¿Qué motivó exactamente que la inclusión de los NNA en las masacres no fuera mínima o excepcional? ¿Cuáles fueron los móviles y las ideas que produjeron a esta particular infancia en el país? Aun cuando las respuestas cargan muchas bifurcaciones y aristas afincadas en los estudios del terror en los escenarios bélicos (Lair, 2003), la transfiguración y la mutación de las representaciones clásicas de la infancia provocada por los códigos de la violencia política resultan un factor explicativo importante para empezar a ahondar en esta problemática.

Cabe destacar que, a los NNA en los contextos bélicos usualmente se les ha asimilado de dos grandes maneras que van en contravía de las habituales consideraciones que los leen como buenos, incapaces, vulnerables, dependientes y víctimas (Cussiánovich, 2004). En primer lugar, la frontera etaria en la que se sostiene la estimación jurídica y cultural en occidente entre NNA y adultos se esfuma (Rosen, 2015). A los NNA se les percibe como adultos en miniatura capacitados para militar, auxiliar y combatir, lo que auspicia que se les mate por igual, con todo y como dice Suárez no siempre se conviertan en objetos de sevicia como ocurre generalmente con "los hombres que se acercan al estereotipo del combatiente [...] a los que se les remata y se les contramata" (2008, p. 73). Por otro lado, a los NNA en los enclaves de la guerra se les sigue interpretando como personas en devenir, como mero futuro, pero en clave negativa al tildárseles de individuos que pueden perpetuar una ideología indeseada o transformarse en intérpretes de venganzas, por lo que en Colombia como en otras partes del mundo, se volvió corriente la tesis de arrancar "las malas hierbas de raíz" (Melvern, 2007), de que "de raíz todito se corte" (Comisión de la Verdad y Reconciliación, 2003, p. 598), de "matar la semilla" (Comisión para el Esclarecimiento Histórico, 1999, p. 61) o de que si te acusaban de ser guerrillero el exterminio se extendiera "a toda tu familia" (Danner, 2016, p. 57). Dos casos emblemáticos lo permiten pensar. Primeramente, el asesinato de Luis Carlos Vélez, un niño de seis años, castrado por el paramilitarismo en la masacre de Mesetas del 13 de septiembre de 1991 acometida 
contra su padre, el diputado del Meta por la Unión Patriótica, Carlos Julián Vélez, en la que uno de los ejecutores señaló: "ese chino ("Luisito"), cuando crezca va a ser el peor cuchillo para nosotros. Es mejor que lo matemos también” (CNMH, 2018c, p. 259). El segundo ejemplo lo brinda la masacre de San José de Apartado ocurrida el 21 de febrero de 2005, en la que en un ejercicio conjunto entre paramilitares del Bloque Héroes de Tolova y la Brigada XVII de Urabá, cinco adultos y tres niños -Andrés Guerra Tuberquia de 11 años, Natalia Tuberquia de 5 años y Santiago Tuberquia de 21 meses- resultaron descuartizados. Tiempo después un testimonio del paramilitar Jorge Luís Salgado, alias Kiko, indicó que la suma del estigma generalizado de una determinada población como guerrillera con la hipótesis de la potencialidad negativa que se le adjudica a los NNA en la guerra había sido clave para decidir sus homicidios:

Se le preguntó al comandante que qué se hacía con estos niños y llegaron a la conclusión de que serían una amenaza en el futuro diciendo textualmente que ellos crecían y se volverían guerrilleros...por ese motivo se ordenó ejecutarlos en silencio (Revista Semana, 2011, s/p).

Ahora bien, que a los NNA se les torture, castre o despedace en el desarrollo de una masacre, es algo que supera cualquier casualidad o la preferencia mortífera del ejecutor. Su puesta en escena explota en favor del victimario la profanación de las simbologías románticas que vinculan a los NNA con entes sagrados, inocentes y puros (Saénz Obregon, 2009; Morente Mejías, 2012). Sin ambages, la conversión de los NNA en objetivos de eliminación y en medios tácitos para comunicar reprobaciones a ciertos perfiles e identidades, se daría para sacarle provecho a la vulneración de las emociones y a las representaciones tradicionales ligadas a la infancia, y por ende, para asestar un golpe simbólico a los destinatarios de los crímenes implementados. Por tanto, la teatralización de la violencia contra los cuerpos de los NNA en las masacres colombianas -como en cualquier otra por su excesiva matriz violenta (Blair, 2005; Lair, 2003)- se distancia de ser gratuita y se sostiene en un sobreesfuerzo para imprimirla en la memoria colectiva en los territorios. ${ }^{5}$ Las viejas y paralelas lecciones enseñadas por las guerras de la región así lo confirman. Según la Comisión para el Esclarecimiento Histórico de Guatemala, en las masacres que practicaron los militares, a los neonatos y preferiblemente a los infantes entre los 0 y los 5 años de edad se les mataba con mayor crueldad, recurriendo a piedras, patadas, palos, cuchillos, o estrellándolos contra las paredes y el piso, para desprender una estela de pánico generalizado y "dejar sentado el mensaje de que no importando la edad serían eliminadas las personas de una comunidad señalada como zona roja”. (Comisión para el Esclarecimiento Histórico, 1999, p. 63). En lo que toca a Colombia, el aprovechamiento de esta máxima fue total, incluso como se ha dicho desde antes. Una masacre partidista de los años cuarenta contra 13 personas en el municipio de Balsillas, Tolima, promete una escena para recordar: "La cabeza de un niño de tres meses la dejan sobre una estaca frente a la del padre ensartada en otro poste de la cerca” (Guzmán Campos, Fals Borda y Umaña Luna, 2014, p. 75).

De tal modo, la investigación de la infancia masacrada en Colombia tiene mucho material para trabajar y se hace urgente por causa de la permanente inclusión de los NNA en estas ejecuciones colectivas y excesivas de violencia. Solamente bastaría para poner a rodar esta empresa, aceptar varios retos metodológicos ineludibles, entre ellos, desagregar los datos publicados, distinguir los modus operandi de las masacres, encontrar tanto la verdad factual como la moral, esto es no únicamente los hechos sino "el por qué” y "a causa de quién” (Blair, 2002, p. 13), y rastrear las masacres exclusivas de NNA que a pesar de no haber sido denunciadas o ser ubicables en ningún reporte público, parecen haber ocurrido como lo sugiere el siguiente relato:

En cuanto a las masacres cometidas por el Bloque Calima, una persona desmovilizada que operó en el suroriente del Valle refirió el homicidio de niños que fueron señalados de colaborarle a la guerrilla, no obstante, en ninguna fuente secundaria pudo encontrarse el registro de un episodio con estas características

Entrevistador: yo te pregunté por algunas acciones violentas me dijiste que masacres ¿qué masacres cometieron que tú recuerdes... en las que el grupo haya matado a más de tres personas?

Entrevistado: Sí, a unos peladitos que vivían por allá, que hacía como 15 días habían hecho la primera comunión, que también los cogieron, que decían que eran colaboradores de la guerrilla entonces subieron y los mataron

Entrevistador: ¿Qué edad tenían estos niños? 
Entrevistado: Estos pelados tenían por ahí entre los diez y ocho años (...) a ellos sí arriba los mataron en la casita de ellos, los sacaron de la casita de ellos y los mataron a los lados de abajo (CNMH-DAV, entrevista hombre desmovilizado, 2015, 1 de julio, Cali). (CNMH, 2018d, p.206)

\section{LA DESAPARICIÓN FORZADA Y LOS NNA}

En contraposición de otras revisiones, la historia de la desaparición forzada de NNA pareciera ser más ardua de organizar y mucho más profusa por la diversidad de sus manifestaciones. Efectivamente, tiende a ser dificultosa porque si la violencia contra los NNA en las masacres se fundaba ante todo en hacer sus muertes visibles, públicas o expuestas a la vista de todos los habitantes de un espacio determinado, en lo que atañe a la desaparición forzada lo común es su encubrimiento o la anulación de cualquier rastro de existencia de las víctimas (Verdadabierta.com, 2017). Algo que, en términos de testimonios, fuentes, datos y pruebas es un escollo gigante para cualquier emprendimiento de una memoria histórica por hacerse, pues obliga a trabajar básicamente con la voz de los responsables o con los testigos delegativos, o sea con "quién presenció un acontecimiento desde el lugar del tercero, que vio algo aunque no tuvo participación directa en el mismo" (Blair, 2008, p. 93). Súmesele a ello, que la historia de la infancia desaparecida forzadamente es de por sí compleja, debido a la carencia de un móvil similar en los lugares donde se ha aplicado. Por ejemplo, en Argentina su realización se alejó de enfocarse totalmente en la supresión física de los NNA -por el rapto de los mismos para familias estériles afines a la dictadura militar con la consiguiente complicidad de funcionarios administrativos y judiciales (Villalta, 2009)- como sí ocurrió a profundidad en el Perú donde hay sentencias de tribunales internacionales que condenan al Estado por hacer de la analogía de desaparecer y matar una realidad (Fowks, 2015).

En Colombia, pese a que la información más actualizada indica que en el conflicto armado la desaparición forzada alcanzó entre 1970 y 2015 a 60.630 personas, en por lo menos, 1.010 de los 1.115 municipios que tiene el país (CNMH, 2016). Llama la atención que esa misma exactitud de datos sea casi imposible de alcanzar en lo correspondiente a la infancia por la precariedad de la información disponible en los perfiles de las víctimas, por la falta de denuncias ante el temor a las represalias y porque los NNA "son menos conocidos en sus comunidades en comparación con los adultos" (Comisión de la Verdad y Reconciliación, 2003, p. 55). Esto da a entender, entre otras cosas, que del total reportado solamente se conozca la edad de un $33,3 \%$ (20.210) y que de esos casos sistematizados 3.217 fueran NNA en un universo que tiende a ser mayor e impreciso estadísticamente, al punto de que de 200 de ellos se desconoce con exactitud su rango etario (CNMH, 2016).

De manera que, adentrarse en la infancia desaparecida precisa enfrentar esos claroscuros y buscar cómo en la experiencia comparada se afrontó el aprieto metodológico de que en estos acontecimientos y vivencias "no es posible testimoniar porque no hay sobrevivientes" (Blair, 2008, p. 92). Habría que mirar entonces, los métodos de recolección de información, la procedencia de los testimonios y las variables de análisis que llevaron a que se concluyera que en El Salvador 888 NNA fueron raptados y exportados por las fuerzas armadas en los años ochenta con las argucias de funcionarios judiciales y notariales (Ocampo Saravia, 2013); que en Argentina, se estableciera que 250 adolescentes fueron desaparecidos durante la dictadura militar de Jorge Videla (Comisión Nacional sobre la Desaparición de Personas, s.f.); que en Chile, la Comisión Nacional de la Verdad y la Reconciliación estimara en 90 a los NNA que el régimen dictatorial de Augusto Pinochet desapareció (1991); o que en Perú, por su parte, se calculara en aproximadamente 582 los NNA desaparecidos en el fragor de la guerra popular entre Sendero Luminoso, el Movimiento Revolucionario Túpac Amaru y la contrainsurgencia del Estado (Bácares, 2011).

El hacerlo contribuiría a restar escollos procedimentales y a imaginar la ruta para que en Colombia se le preste atención a esta infancia subsumida y prácticamente desapercibida en los macro informes sobre la desaparición forzada. De su investigación detallada puede derivarse una clarificación de las razones, las causas, 
las formas, los perpetradores y las consecuencias que a lo largo del tiempo impulsaron y provocaron a estos NNA. Inclusive, ver la manera en que el paradigma de la protección, la debilidad y la candidez asociado comúnmente a la infancia occidental fue utilizado a la hora de ejecutarse la desaparición forzada para generar un mayor miedo y zozobra en la población civil y en los grupos en contienda aprovechando las mentalidades y signos sentimentales adjudicados a los NNA. Si de por sí, este delito continuado se consuma para romper las redes familiares y los vínculos sociales de una comunidad y de los declarados como enemigos (Bácares, 2011), al obligar a vivir "la imposibilidad de entrar en luto" (Lair, 2003, p. 102), vale la pena deliberar la capacidad hipotética de daño que en la gente cercana a los NNA desaparecidos indujo esta acción por el mero hecho de que las víctimas directas fueran justo NNA, depositarios de unas determinadas imágenes sociales que los definen y diferencian de los adultos, como su fragilidad o su falta de responsabilidad en las tramas políticas, económicas y militares.

Así, unos abordajes de tipo cualitativo ayudarían a aclarar un sinfín de asuntos todavía carentes de escritura y verdad: ¿Por qué, por ejemplo, la desaparición forzada se concentró entre los 15 y 17 años, con 1.694 víctimas de 1970 a $2015(\mathrm{CNMH}, 2016)$ ? ¿O a la inversa, qué hizo que en 234 episodios se desapareciera sujetos de la primera infancia, de 0 a 5 años en el mismo ciclo de tiempo (CNMH, 2016)? ¿Las contestaciones se asocian acaso a la propuesta de "un castigo ejemplar" a la organización social y la población civil donde las guerrillas han tenido importancia (Ocampo Saravia, 2013)? Además, falta por saber: ¿Cuáles han sido las implicaciones en la salud mental de los deudos de los desaparecidos de NNA? ¿Si la desaparición forzada de NNA se concentró en algún lugar, región específica, sexo y afiliación política? ¿Si es un crimen predominantemente estatal, guerrillero o paramilitar? ¿Si hay más casos como el del nieto de Ramón Isaza, comandante paramilitar de las Autodefensas del Magdalena Medio, que en 1996 fue arrebatado siendo bebé de sus padres, dos guerrilleros recién desaparecidos? (Revista Semana, 2007) o ¿Cómo se ha trabajado y cuánto ha avanzado el tema de la reparación, la justicia y la verdad en lo que concierne a la niñez desaparecida en el conflicto armado colombiano?

Sobre esto último, el delito de la desaparición forzada en los NNA es incompatible con la anulación de su estatus de sujetos de derechos a causa de su evidente muerte o desvanecimiento físico. Cada NNA desaparecido por el quehacer bélico -y por extenso sus sobrevivientes- obligan al Estado a garantizarles los derechos a la verdad, a la justicia y a la reparación (Bácares, 2011). Por ahora, los avances en estas tres ramas son mínimos y precarios, ya que producto de lo pactado en el Acuerdo de La Habana, la recién creada Unidad de Búsqueda de Desaparecidos tiene un funcionamiento retrasado por la falta de asignaciones presupuestales (Revista Semana, 2018) y desde un tiempo pretérito, porque el foco en materia institucional ha sido la exhumación y búsqueda de fosas clandestinas por parte de la Fiscalía General de la Nación, que derivaron hasta hoy en la recuperación de 3.921 restos óseos de desaparecidos. A propósito de esto, los descubrimientos de NNA han estado a la orden del día, lo que ratifica la importancia de recuperar el habla para estas víctimas en una narración pública llamada memoria histórica (Gómez Muller, 2008). Precisamente, el cuerpo número mil que fue identificado correspondió al de Noralba Camargo, una niña de 13 años que en el 2000 fue raptada y asesinada por el Bloque Héroes de Gualivá en Quebradanegra, Cundinamarca, por el señalamiento de ser auxiliadora de la insurgencia en la zona (Rodríguez, 2017).

\section{LA VIOLENCIA SEXUAL Y LOS NNA}

Las interpretaciones investigativas relacionadas con las violencias que el conflicto armado le ha propinado a las niñas a menudo se han decantado por subrayar su faceta de víctimas en parangón de una que otra excepción abocada a poner la lupa en su agencia (Boyden y De Berry, 2004; Carmona Parra, 2013; Higonnet, 2011; Páez, 2001). De esto da fe, lo que versa y gira en torno a la violencia sexual, que por supuesto es un tema carente y urgido de memoria histórica, dado que en las sociedades patriarcales lo habitual es que se le silencie por vergüenza, estigmatización social y por miedo a los señalamientos y vendettas (Franco, 2016; heidon, 2015). 
En atención a esto, escrutar a la infancia violentada sexualmente en la guerra colombiana carga la obligación de cuestionar los discursos que la relativizan y que la proponen como natural, accidental e inevitable -sin dejar claro de posicionar las facetas activas de los NNA y sus mecanismos para resistirla- (Silva Santiesteban, 2015). De momento, unos cuantos textos rigurosos latinoamericanos han evidenciado cómo los soldados peruanos en el enfrentamiento contra senderista violaban a las mujeres en las mismas fosas en las que a la nada iban a ser enterradas o como con la promesa de que se les liberaría, se hacía lo mismo con ellas en salas de interrogatorios clandestinas, siempre con la aquiescencia y asentimiento de sus superiores (Uceda, 2004). Igualmente, en el cono sur y en Centroamérica hay otros casos probados que desmienten una violencia sexual espontánea o carente de una intención represiva. Durante la dictadura chilena por ejemplo fue aceptado que a las adolescentes detenidas se les violara con perros amaestrados (Comisión Nacional sobre Prisión Política y Tortura, 2005); y en el conflicto guatemalteco que a 512 niñas (40, entre los 0 y 5 años) se les violara frente a sus padres como una estratagema de castigo en largas jornadas en los cuarteles y en los campos (Comisión para el Esclarecimiento Histórico, 1999).

En Colombia, los reportorios de la violencia sexual efectuados por los actores armados legales e ilegales, a su vez, alcanzaron a los NNA para amedrentar y punir a los allegados y a quienes intimaron con los bandos contrarios (CNMH, 2012). Las exiguas cifras que están a disposición de los investigadores revelan que entre 2008 y 2012 se registraron, fruto de la guerra, 41.313 niñas y 7.602 niños atacados sexualmente (Coalico, 2014). En muchos de esos episodios, la meta perseguida respondería a lo ya trazado: dañar a los progenitores, parientes y a los militantes políticos de las organizaciones antónimas de los victimarios. Tal cual acaeció, entre muchas historias por ubicar, con Alida Teresa Arzuaga Villar, una niña de 9 años que de acuerdo con una sentencia judicial del Tribunal Superior de Bogotá fue violada y asesinada por miembros de las Autodefensas Campesinas de Puerto Boyacá el 9 de junio de 2005 como una retaliación contra su padre, que en ese momento se encontraba preso en la Cárcel Modelo de Bucaramanga, acusado de colaborar con el Ejército de Liberación Nacional:

La menor de nueve años, ALIDA TERESA ARZUAGA VILLAR, fue desaparecida por integrantes de las ACPB cuando iba del colegio a su vivienda, ubicada en la zona rural en el municipio de Zapatoca (Santander). La niña fue vista por última vez, a las cuatro de la tarde, en el parque del municipio. Al día siguiente, aproximadamente a las 8:30 horas, en la Vereda Santa Rosa, Finca Buenos Aires, fue hallado su cadáver a unos 300 metros de su vivienda, en una zona boscosa, el cual presentaba signos visibles de agresión sexual. El paramilitar LUIS EDUARDO SANDOVAL delató a HERNANDO RODRÍGUEZ ZARATE, alias "Volunto", comandante del Frente Ramón Danilo de las ACPB, como responsable de los crímenes, y precisó que, el móvil fue por venganza contra FARID ARZUAGA, padre de la menor, quien para la época de los hechos se encontraba privado de la libertad por rebelión, y a quien se le señalaba de ser informante de la guerrilla y responsable de la muerte de unos paramilitares de las ACPB. (Sentencia Arnubio Triana Mahecha y otros, 2014, p. 101)

En otro orden de ideas, a la indagación de la infancia tratada en este acápite le cabe otro gran reto: el de encontrar, anotar y ampliar por regiones, frentes, y orígenes bélicos, los visos especializados y los dispositivos inusitados de la violencia sexual que las organizaciones partícipes del conflicto armado les impusieron a los NNA y en un prueba distinta encontrar las formas de resistencia que, con o sin éxito, las comunidades, las propias niñas y sus pares forjaron para protegerse de las mismas. Por ejemplo, en las guerrillas, está documentado que varios comandantes negociaron el canje de niñas para inhibirse de reclutar a los demás hijos de las familias oferentes y que a las combatientes de menor rango se les obligaba a pasar por un control de natalidad dentro de la tropa o en su defecto por abortos forzados (CNMH, 2013). ¿Sobre este particular, sería una tarea de la memoria que se construya sobre esta infancia, dilucidar si los tiempos de la guerra o las presiones militares de la confrontación determinaron que en unas épocas y territorios la vigilancia de los embarazos y nacimientos fuese más agresivo que en otras, o enseñar si el privilegio de la natalidad en realidad fue sólo para las mujeres asociadas a un jerarquía importante o a la compañía de un guerrillero con mando?

De igual manera, la gran logística y las estrategias que el paramilitarismo implementó para controlar a la población civil por medio de la violencia sexual esconden todavía sorpresas insospechadas, sobre todo, 
por las alianzas construidas con escuelas, rectores, padres de familia y otros intermediarios anónimos que facilitaron violaciones y abusos (Revista Semana, 2016). Seguramente, siguiendo por ese camino hay mucho por encontrar y para hacer público. Y es que, el parentesco forjado entre una buena parte de los habitantes de la sierra nevada de Santa Marta con el jefe del Frente Resistencia Tayrona del Bloque Norte, Hernán Giraldo, para la victimización de sus hijas o los concursos de belleza escolares organizados por los jefes del Bloque Héroes de Montes de María con la misma intención sirven para presentir los hallazgos que propicie esta búsqueda (CNMH, 2011b). Finalmente, no está de más recalcar, tomando en cuenta los parámetros éticos de la memoria histórica (Gómez Muller, 2008) que dicha exploración debería partir de un relato afincado en los requerimientos de las víctimas y en sus rememoraciones en primera persona para conocer además de los fundamentos de los victimarios, las repercusiones y las formas de encarar la violencia sexual que las y los tuvo como destinatarios cuando eran menores de edad.

\section{A MODO DE REFLEXIONES FINALES}

Sólo cuando se convierte en relato el mundo al fin parece comprensible (Ospina, 2008, p. 106).

Que la infancia sea un hecho socialmente producido y plural supone que la memoria histórica de la infancia en la guerra sea variada, amplísima, diacrónica y dependiente de una hilera de variables sociales, culturales, políticas y económicas (James y Prout, 1997). De esta forma, los modos de vida y los contactos con la parca creados por la violencia política para los NNA son diferentes y están en permanente constitución y conexión con sus posturas, maniobras, incursiones, directrices, resistencias y planeaciones. Por lo cual, si una parte de un conflicto armado recurre -entre miles de acciones- a sembrar o lanzar explosivos artesanales, lo que hace en el fondo, es dar pie a unas nuevas expresiones de ser NNA en las hostilidades que antes no existían ni son naturales, como lo detallan los 48 NNA que murieron en la masacre de Bojayá, en el Chocó en el 2002 (CNMH, 2010) o Maryi Vanessa Coicué, una niña indígena nasa, quien murió por un cilindro bomba disparado por las Farc-Ep en el 2011 (Rodríguez y Restrepo, 2012).

Por ello, la invitación a redactar una memoria histórica de las infancias en la guerra, a saber, a ponerlas en el centro de un relato público para evitar su ocultamiento, el desconocimiento de su victimización y su explicación socio histórica, depende de la propia mutabilidad y diversificación de esta categoría al entrar en contacto con el conflicto armado. Justamente, de esa interacción surge un extensísimo ramillete de infancias dado que estos fenómenos, como todos los infantiles y adolescentes, "son hechos por la sociedad, producidos socialmente, producto de relaciones sociales” (Sánchez Parga, 2004, p. 18). Bajo esta lógica, las infancias por reseñar, dar a conocer y pormenorizar en términos de su elaboración social por las órdenes y acciones militares son muchas. Saltan a la vista, aparte de las propuestas en estas notas, la de los NNA secuestrados, ${ }^{6}$ la de los NNA víctimas de minas antipersonales, la de los NNA que tienen en veremos el derecho a educarse por las presiones armadas sobre la escuela (Romero Medina, 2013), la de los NNA obligados a la orfandad, o la de los NNA ejecutados extrajudicialmente, que en el país -ya fuese ante combatientes natos o personas asesinadas para hacerlas pasar más tarde por guerrilleros dados de baja en combate- tiene una fecunda y desconocida historia por explorarse desde los años cincuenta (Palacios, 2012).

En síntesis, ante la restringida atención a las infancias emanadas del conflicto armado colombiano resulta trascendental dar comienzo a una memoria histórica verdaderamente plural y dialogante con todas las víctimas, o en otras palabras, a una memoria histórica que le haga el quite al relato adultocéntrico, basado en la centralidad del adulto y en la negación del alcance generacional que tuvo la guerra. Al encaminarse esta perspectiva, las investigaciones por idearse y desarrollarse por un tiempo carecerían de bifurcaciones temáticas. Claramente, para su realización hay que ir más allá de aplicar el enfoque diferencial, siendo lo primario generar un horizonte de sentido para las infancias más diferidas de las narraciones oficiales y contra oficiales, tal como, ser creativos metodológicamente partiendo de los avances que en esta materia se han hecho 
en otros lugares del mundo y acogiendo las voces infanto-adolescentes y sus dispositivos de memoria -diarios, cartas, grabaciones- como elementos complementarios de una versión adulta de la guerra que habitualmente los reduce a víctimas y rechaza otras dimensiones de los NNA como las de protagonistas y testigos de las experiencias bélicas (Castillo Gallardo, 2015).

\section{ReFERENCIAS}

Alcubierre, B. y Carreño King, T. (1996). Los Niños Villistas. Una mirada a la historia de la infancia en México, 1900-1920. Ciudad de México: Instituto Nacional de Estudios Históricos de la Revolución Mexicana.

Alexiévich, S. (2016). Últimos testigos: los niños de la segunda guerra mundial. Bogotá: Debate.

Alonso Carballes, J. (1998). 1937. Los niños vascos evacuados a Francia y Bélgica. Historia y memoria de un éxodo infantil, 1936-1940. Bilbao: Asociación de Niños Evacuados el 37.

Bácares, C. (2019). El protagonismo de la infancia en las Comisiones de la Verdad: desafíos y retos para el posconflicto en Colombia. Ciencia Politica, 14(27), 19-46. https://doi.org/10.15446/cp.v14n27.73183

Bácares, C. (2017). Siete tesis para una lectura multidimensional y en larga duración del reclutamiento ilícito de los niños, niñas y adolescentes en Colombia. Cuadernos de Marte. Revista Latinoamericana de Sociología de la Guerra,8(12), 255-316. Recuperado de https://publicaciones.sociales.uba.ar/index.php/cuadernosdemarte/art icle/view/2392

Bácares, C. (2014). Los pequeños ejércitos. Las representaciones sobre la vida y la muerte de los niños, niñas y jóvenes desvinculados de los grupos armados ilegales colombianos. Bogotá: Editorial Magisterio.

Bácares, C. (2011). La desaparición forzada de los niños, niñas y adolescentes durante la violencia política en el Perú: una historia de desafiliaciones e impunidad". En R. Soto (Ed.), El Estado y el ejercicio ciudadano de la infancia en la sociedad peruana en los albores del siglo XXI (pp. 90-143). Huancayo: Universidad Nacional del Centro del Perú.

Blair, E. (2002). Memoria y Narrativa: La puesta del dolor en la escena pública. Estudios Políticos, 21, 9-28. Recuperado de https://revistas.udea.edu.co/index.php/estudiospoliticos/article/view/1413/1490

Blair, E. (2005). Muertes violentas. La teatralización del exceso. Medellín: Editorial Universidad de Antioquia.

Blair, E. (2008). Los testimonios o las narrativa(s) de la(s) memoria(s). Estudios Políticos, 32, pp. 85-115. Recuperado de https://revistas.udea.edu.co/index.php/estudiospoliticos/article/view/1249/979

Boyden, J. y De Berry, J. (Ed). (2004). Children and youth on the front line. Ethnography, armed conflict and displacement. New York: Berghahn Books.

Cárdenas, Y. (2018). Experiencias de infancia. Niños, memorias y subjetividades (Colombia, 1930-1950). Bogotá: Universidad Pedagógica Nacional.

Carmona Parra, J. (2013). Las niñas de la guerra en Colombia. Manizales: Universidad Católica de Manizales.

Casal, S. (2017). Diario de una infancia. Mariana. Secuencia. Revista de historia y ciencias sociales, 99, 185-207. https ://doi.org/10.18234/secuencia.v0i99.1398

Castillo Gallardo, P, Peña Fredes, N, Garrido, M, González Bertran, A, y Trujillo Arredondo, F. (2017). Recuerdos de infancia: niñez y dictadura en Chile (1973-1990). Kamchatka. Revista de análisis cultural, 10(diciembre), 447-471. https://doi.org/10.7203/KAM.10.9973

Castillo Gallardo, P. (2015). Infancia en dictadura. Niñas y niños testigos: sus producciones como testimonio. Santiago de Chile: Colectivo Infancia y Memoria.

Castillo Gallardo, P. y Gonzáles Celis, A. (2019). (Eds.). El Diario de Francisca. 11 de septiembre de 1973. Santiago de Chile: Editorial Hueders.

Castillo Gallardo, P. y Gonzáles Celis, A. (2013). Niñez en dictadura: lo filiativo como espacio de resistencia. Revista de Geografia Espacios, 3(6), 117-131. https://doi.org/10.25074/07197209.6.356

Castillo Gallardo, P. y Gonzáles Celis, A. (2015). Infancia, dictadura y resistencia: hijos e hijas de la izquierda chilena (1973-1998). Revista Latinoamericana de Ciencias Sociales, Niñez y Juventud, 13(2), 907-921. https://doi.org/ $10.11600 / 1692715 x .13225290914$ 
Cenarro, A. (2009). Los niños del auxilio social. Madrid: Espasa.

Centro Nacional de Memoria Histórica (CNMH). (2009). El salado. Esa guerra no era nuestra. Bogotá: CNMH.

Centro Nacional de Memoria Histórica (CNMH). (2010). Bojayá: la guerra sin límites. Bogotá: CNMH.

Centro Nacional de Memoria Histórica (CNMH). (2011a). La masacre de El Tigre. Un silencio que encontró su voz. Bogotá: $\mathrm{CNMH}$.

Centro Nacional de Memoria Histórica (CNMH). (2011b). Mujeres y guerra. Victimas y resistentes en el caribe colombiano. Bogotá: CNMH.

Centro Nacional de Memoria Histórica (CNMH). (2011c). San Carlos: memorias del éxodo en la guerra. Bogotá: $\mathrm{CNMH}$.

Centro Nacional de Memoria Histórica (CNMH). (2012). El Placer. Mujeres, coca y guerra en el bajo Putumayo. Bogotá: CNMH.

Centro Nacional de Memoria Histórica (CNMH). (2013). ¡Basta ya! Colombia: memorias de guerra y dignidad. Bogotá: CNMH.

Centro Nacional de Memoria Histórica (CNMH). (2014). Desafíos para la reintegración. Enfoques de género, edady etnia. Bogotá: CNMH.

Centro Nacional de Memoria Histórica (CNMH). (2016). Hasta encontrarlos. El drama de la desaparición forzada en Colombia. Bogotá: CNMH.

Centro Nacional de Memoria Histórica (CNMH). (2017). Una guerra sin edad. Informe nacional de reclutamiento y utilización de niños, niñas y adolescentes en el conflicto armado colombiano. Bogotá: CNMH.

Centro Nacional de Memoria Histórica (CNMH).(2018a). Memorias plurales. Balance de la contribución del CNMH al esclarecimiento histórico. Bogotá: CNMH.

Centro Nacional de Memoria Histórica (CNMH). (2018b). Violencia paramilitar en la altillanura: Autodefensas Campesina de Meta y Vichada. Informe $N^{\circ} 3$. Serie: informe sobre el origen y la actuación de las agrupaciones paramilitares en las regiones. Bogotá: CNMH.

Centro Nacional de Memoria Histórica (CNMH). (2018c). Todo pasó frente a nuestros ojos. El genocidio de la Unión Patriótica 1984-2002. Bogotá: CNMH.

Centro Nacional de Memoria Histórica (CNMH). (2018d). Bloque Calima de las AUC. Depredación paramilitar y narcotráfico en el suroccidente colombiano. Informe $N^{\circ} 2$ Serie: Informes sobre el origen y actuación de las agrupaciones paramilitares en las regiones. Bogotá: CNMH.

Coalico (Coalición contra la vinculación de niños, niñas y jóvenes al conflicto armado en Colombia). (2014). iQue dejen de cazar a las niñas y los niños! Informe sobre violencia sexual contra niñas, niños y adolescentes en el conflicto armado en Colombia. Bogotá: Campaña Violaciones y otras violencias: saquen mi cuerpo de la guerra.

Comisión de la Verdad y Reconciliación. (2003). Cuarta parte: recomendaciones de la CVR, hacia un compromiso nacional por la reconciliación. Capítulo 2, Recomendaciones. En Comisión de la Verdad y Reconciliación, Informe final (tomo IX). Recuperado de http://www.cverdad.org.pe/ifinal/pdf/TOMO\%20IX/2.INTRODU CCION\%20RECOMENDACIONES.pdf

Comisión de la Verdad y Reconciliación. (2003). Sección cuarta: los crímenes y violaciones de derechos humanos. Capítulo 1: Patrones en la perpetración de los crímenes y de las violaciones de los derechos humanos. 1.8 La violencia contra los niños y niñas. En Comisión de la Verdad y Reconciliación, Informe final (tomo VI). Recuperado de http://www.cverdad.org.pe/ifinal/index.php

Comisión Nacional de Verdad y Reconciliación. (1991). Nombres y Datos Biográficos de la Víctimas. En Comisión Nacional de Verdad y Reconciliación, Informe de la Comisión Nacional de Verdady Reconciliación, (Vol. II. Tomo 3). Santiago, Chile: Corporación Nacional de Reparación y Reconciliación. Recuperado de http://www.fasic.o $\mathrm{rg} /$ tomo3.pdf

Comisión Nacional sobre la Desaparición de Personas. (s.f.). El nunca más y los crimenes de la dictadura. Buenos Aires, Argentina: Cultura Argentina. Recuperado de: http://librosycasas.cultura.gob.ar/wpcontent/uploads/2015/1 1/LC_NuncaMas_Digital1.pdf 
Comisión Nacional sobre Prisión Política y Tortura. (2005) Informe de la Comisión Nacional sobre Prisión Política y Tortura. Santiago de Chile: Ministerio del Interior. Recuperado de http://bibliotecadigital.indh.cl/handle/12 $3456789 / 455$

Comisión para el Esclarecimiento Histórico. (1999). Guatemala, memoria del silencio. Ciudad de Guatemala, Guatemala: Oficina de Servicios para Proyectos de las Naciones Unidas. Recuperado de http://www.centrodem emoriahistorica.gov.co/descargas/guatemala-memoria-silencio/guatemala-memoria-del-silencio.pdf

Comisión Verdad y Justicia. (2008). Informe Final, Anive haguâ oiko. Las violaciones de Derechos de Algunos Grupos en Situación de Vulnerabilidad y Riesgo, (Tomo III). Asunción, Paraguay: Comisión Verdad y Justicia Paraguay CVJ. Recuperado de http://www.verdadyjusticia-dp.gov.py/pdf/informe_final/Tomo\%203.pdf

Comisión Verdad y Justicia. (2008). Informe Final, Anive haguâ oiko. Sintesis y Caracterización del Régimen, (Tomo I). Asunción, Paraguay: Comisión Verdad y Justicia Paraguay - CVJ. Recuperado de http://www.verdadyjustic ia-dp.gov.py/pdf/informe_final/Tomo\%201\%20-\%20Parte\%201.pdf

Commission for Reception, Truth and Reconciliation. The Timor-Leste. (2013). Chega! The Final Report of the TimorLeste Commission for Reception, Truth and Reconciliation (CAVR). (Vol. 1). Jakarta, Indonesia: KPG y STPCAVR. Recuperado de: http://chegareport.net/Chega\%20All\%20Volumes.pdf

Correa, A. (2015). "Niños, niñas y jóvenes en la restitución de tierras. Análisis de fallos de restitución de tierras a favor de menores de edad". (Tesis de Especialización). Universidad Nacional de Colombia. Bogotá.

Cussiánovich, A. (2004). Aún yo no soy. En Aprodeh (Ed.) “Hasta sus menorcitos ahora lloran...”. 1980-2000: Violencia contra niños, niñas y adolescentes. Selección de textos del Informe Final de la Comisión de la Verdad y la Reconciliación (pp. 11-25). Lima: Aprodeh.

Danner, M. (2016). Masacre: la guerra sucia en El Salvador. Barcelona: Malpaso Ediciones.

Egaña, I. (2009). Los crimenes de Franco en Euskal Herria 1936-1940. Tafalla: Txalaparta.

El Espectador. (2017). Asesinato de Mario Calderón y Elsa Alvarado es un crimen de lesa humanidad. Recuperado de https://www.elespectador.com/noticias/judicial/asesinato-de-mario-calderon-y-elsa-alvarado-es-de-lesa-hu manidad-articulo-693493

Filipović, Z. (1994). Diario de Zlata. Madrid: Editorial Aguilar.

Filipović, Z. y Challenger, M. (Eds.). (2007). Voces robadas. Diarios de guerra de niños y adolescentes desde la Primera Guerra Mundial hasta Irak. Barcelona: Ariel.

Fowks, J. (2015, noviembre 15). La CIDH sanciona a Perú por la desaparición forzada de niños. El País. Recuperado de: https://elpais.com/internacional/2015/11/14/america/1447534245_337896.html

Franco, J. (2016). Una modernidad cruel. Ciudad de México: Fondo de Cultura Económica.

Gaitán, L. (2006). La nueva sociología de la infancia. Aportaciones de una mirada distinta. Política y Sociedad, 43(1), 9-26. https://dx.doi.org/10.5209/POSO

Gil, F. y García, A. (2009). La mortalidad en la infancia durante la Guerra Civil. Impacto territorial estimado a partir del Censo de 1940. Reis, 127, 55-91.

Gobierno de Colombia y Unidad para las Víctimas (5 octubre 2018). Registro único de víctimas. Recuperado de https ://www.unidadvictimas.gov.co/es/registro-unico-de-victimas-ruv/37394

Gómez Muller, A. (2008). La reconstrucción de Colombia. Escritos politicos. Medellín: La Carreta Editores.

Guzmán Campos, G., Fals Borda, O. y Umaña Luna, E. (2014). La violencia en Colombia. Tomo I. Bogotá: Punto de Lectura.

Hernández, J. (2009). Las 50 grandes masacres de la historia. Barcelona: Tempus.

Herrera Durán, N. (2019). Agente de la Sijín que tendría nexos con paras no será indemnizado por la muerte de su padre. El Espectador. Recuperado de https://www.elespectador.com/colombia2020/justicia/agente-de-la-sijinque-tendria-nexos-con-paras-no-sera-indemnizado-por-la-muerte-de-su-padre-articulo-881786

Higonnet, M. (2011). Girl soldiers in world war I: Marina Yurlova and Sofja Nowosielska. En D. Cook y J. Wall (Ed.). Children and armed Conflict: cross-disciplinary investigations (pp. 7-21). New York: Palgrave Macmillan. 
Hoyos, M. (2016). Las violaciones a los derechos humanos durante la aplicación del estatuto de seguridad (1978-1982): tres décadas de luch a por la memoria. (Tesis de Maestría). Universidad Nacional de la Plata. La Plata.

ICTJ. (2014). La comisión de la verdad indígena de Maine cumple su primer año. Recuperado de https://www.ictj.o $\mathrm{rg} / \mathrm{es} /$ news/comision-verdad-indigena-maine-cumple-primer-ano

Ila, P., Ávila, A., Arias, A., Núñez, P. y Caicedo, M. (2009). Aproximación a los impactos del conflicto armado en la primera infancia en tres regiones del país: Putumayo, Magdalena medio y Arauca. En A. Mejía y G. González Uribe (Ed.). Colombia: huellas del conflicto en la primera infancia (pp.151-269). Bogotá, Colombia: Save the Children.

James, A. y Prout, A. (Eds.). (1997). Constructing and reconstructing childhood. Contemporary issues in the sociological study of childhood. London: Routledge Falmer Press.

Jara Gómez, J. (2017). Cuadernos de la violencia. Memorias de infancia en Villarica y Sumapaz. Bogotá: Cajón de Sastre.

Jaramillo Marín, J. (2014). Pasados y presentes de la violencia en Colombia: estudios sobre las comisiones de investigación (1958-2011). Bogotá: Editorial Pontificia Universidad Javeriana.

Jelin, E. (2012). Los trabajos de la memoria. Lima: Instituto de Estudios Peruanos.

Lair, E. (2003). Reflexiones acerca del terror en los escenarios de guerra interna. Revista de Estudios Sociales, 15, pp. 88-108. https://doi.org/10.7440/res15.2003.06

Llobet, V. (2015a). “Y yo, ¿̇ónde estaba entonces?”. Infancia, memoria y dictadura. Horizontes Sociológicos, 3, 46-57.

Llobet, V. (2015b). ¿Y vos qué sabés si no lo viviste? Infancia y dictadura en un pueblo de provincia. A contracorriente. A Journal on Social History and Literature in Latin America, 12, 1-41.

Llobet, V. (2016). "Eso era lo normal”. Ser niño en la dictadura: un debate sobre la subjetividad y la política. Entramados y perspectivas. Revista de la carrera de sociología, 6, 1-30.

López Blanch, H. (2010). Las mascotas de la guerra. La Habana: Casa Editora Abril.

Machel, G. (1996). El impacto de los conflictos armados sobre los niños. Informe de ONU pide medidas para proteger a los niños de los conflictos armados. Naciones Unidas, A/51/306.

Medina Gallego, C. (1996). ELN: una historia contada a dos voces. Bogotá: Rodríguez Quito Editores.

Mejía Duque, J. (1982). Los niños torturadores: otra aberración del somocismo. Revista Consigna, 6(200), 31.

Melvern, L. (2007). Un pueblo traicionado. El papel de Occidente en el genocidio de Ruanda. Barcelona: Intermón Oxfam.

Molano, A. (1999). Trochas y fusiles. Bogotá: El Áncora Editores.

Molano, A. (2017, febrero 17). Los niños y la guerra. El Espectador. Recuperado de https://www.elespectador.com/ opinion/columna-48

Morente Mejías, F. (2012). Visiones de la infancia y la adolescencia: notas para una concepción alternativa. Revista de la Asociación de Sociología de la Educación, 5(2), 240-257.

Nash, M. y Tavera, S. (Eds.). (2003). Las mujeres y las guerras. El papel de las mujeres en las guerras de la edad antigua a la contemporánea. Barcelona: Icaria Editorial.

Ocampo Saravia, T. (2013). Guerra y desaparición forzada de infantes en El Salvador (1980-1984). Cultura y representaciones sociales, 8(15), 186-216. Recuperado de http://www.culturayrs.unam.mx/index.php/CRS/arti cle/view/407/407

Ospina, W. (2008). El país de la Canela. Bogotá: La otra Orilla.

Osuna, J. (2008). El niño que sobrevivió a los paras. Recuperado de https://verdadabierta.com/el-nino-que-sobreviv io-a-los-paras-1

Oxfam y Casa de la Mujer. (2010). Primera encuesta de prevalencia. Violencia sexual en contra de las mujeres en el contexto del conflicto armado colombiano. Colombia 2001-2009. Recuperado de https://www.oxfamintermon.org/sites/default/files/documentos/files/101206_ Primera_Encuesta_de_Prevalencia.pdf 
Pachón Castrillón, X. (2016). En busca de los niños combatientes en la época de La Violencia en Colombia. Actas VIII Congreso Infancia y violencia. Escenas de un drama. Recuperado de http://www.tramayfondo.com/actividade s/viii-congreso/conferencias/pachon-catrillon_ninos-combatientes-epoca-violencia-colombia.pdf

Paéz, E. (2001). Las niñas en el conflicto armado en Colombia. Bogotá: Terre des hommes; Save the Children.

Palacios, M. (2012). Violencia pública en Colombia 1958-2010. Ciudad de México: Fondo de Cultura Económica.

Parmar, S. Roseman, S. Siegrist, S. y Sowa, T. (2010). Children and transitional justice. Trubt-Telling, Accountability and Reconciliation. Recuperado de https://www.unicef-irc.org/publications/pdf/tj_publication_eng.pdf

República de Colombia. (2017) Presidencia de la República. Decreto 588: Por el cual se organiza la Comisión para el Esclarecimiento de la Verdad, la Convivencia y la no Repetición. Recuperado de: http://es.presidencia.gov.co/no rmativa/normativa/DECRETO\%20588\%20DEL\%2005\%20DE\%20ABRIL\%20DE\%202017.pdf

Revista Semana (2007, mayo 5) "El niño que se robaron los Isaza”. Recuperado de https://www.semana.com/nacion /recuadro/el-nino-robaron-isaza/129745-3

Revista Semana (2009, noviembre 4) “¿Por qué mataron a los niños?”. Recuperado de http://www.semana.com/nac ion/articulo/por-que-mataron-ninos/101939-3

Revista Semana (2016, octubre 4). Así operaba la rectora que entregaba niños a los 'paras' en Charalá. Recuperado de https://www.semana.com/nacion/articulo/la-rectora-que-convertio-a-estudiantes-en-esclavas-sexuales-de-p aramilitares/468930

Revista Semana (2018, enero 16). La búsqueda de desaparecidos no aparece en la agenda política. Recuperado de: https://www.semana.com/nacion/articulo/unidad-de-busqueda-de-desaparecidos-en-colombi a-aun-no-empieza-a-funcionar $/ 553856$

Rodríguez Bautista, N. y García, A. (2017). ¡Papá, son losmuchachos! Asínació el Ejército de Liberación Nacional (ELN) en Colombia. Bogotá: Ocean Sur-La Fogata Editorial.

Rodríguez Rojas, D. (2017, junio 30). La Secreta: del miedo a la esperanza y el progreso. El Espectador. Recuperado de: https://colombia2020.elespectador.com/territorio/la-secreta-del-miedo-la-esperanza-y-el-progreso

Rodríguez, I. (2010, septiembre 9). El desaparecido número 1.000. Recuperado de http://www.verdadabierta.com/v ictimas-seccion/desaparecidos/2697-el-desaparecido-numero-1000

Rodríguez, M. y Restrepo, F. (2012). No hay dolor ajeno. Bogotá: Fundación Cine Documental.

Rojas Rodríguez, J. y Romero Silva, M. (2000). Esta guerra no es nuestra. Niños y desplazamiento forzado en Colombia. Bogotá: CODHES-Unicef.

Romero Medina, F. (2013). Conflicto armado, escuela, derechos humanos y DIH en Colombia. Análisis Político, 77, 57-84. Recuperado de https://revistas.unal.edu.co/index.php/anpol/article/view/44001/45250

Rosen, D. (2005). Armies of the Young: Child Soldiers in War and Terrorism. New Brunswick: Rutger University Press.

Rosen, D. (2015). Child soldiers in the western imagination: from patriots to victims. New Brunswick: Rutger University Press.

Sáenz Obregón, J. (2009). Formación: infantilización y autocreación. En J. E. Martínez Posada y F. Neira (Eds.), Cátedra Lasallista. Miradas sobre la subjetividad (pp. 89-114). Bogotá: Universidad de La Salle.

Sánchez Parga, J. (2004). Orfandades infantiles y adolescentes: introducción a una sociología de la infancia. Quito: Editorial Abya Yala.

Sánchez, G. (2017). Reflexiones sobre genealogía y políticas de la memoria en Colombia. Análisis político, 31(92), 96-114. https://doi.org/10.15446/anpol.v31n92.71101

Sentencia Arnubio Triana Mahecha y otros. (2014). Rad. 11001-22-52000-2014-00058-00 Rad. Interno 2358, Tribunal Superior de Bogotá. Sala de Justicia y Paz, 101 (Bogotá).

Sierra, V. (2009). Palabras huérfanas. Los niños y la Guerra Civil. Madrid: Taurus.

Silva Santiesteban, R. (2015, octubre 6). La deuda con las mujeres violadas. Diario La República. Recuperado de http s://larepublica.pe/politica/886495-la-deuda-con-las-mujeres-violadas/ 
Simarro, C. (2015). Diario de una niña en tiempos de guerra y exilio (1938-1994). De Matadepera (España) a Ciudad de México. En Sosenski, S. (Ed). Ciudad de México: Universidad Nacional Autónoma de México, Universidad Nacional de Educación a Distancia, Centro de estudios de migraciones y exilios.

Sosenski, S. y Osorio Gumá, M. (2012). Memorias de infancia. La Revolución mexicana y los niños a través de dos autobiografías. En S. Sosenski, y E. Jackson Albarrán (Eds.). Nuevas miradas a la historia de la infancia en América Latina. Entre prácticas y representaciones (pp. 153-175). Ciudad de México: Universidad Nacional Autónoma de México.

Suárez, A. (2008). La sevicia en las masacres de la guerra colombiana. Análisis Político, 63, 39-57. Recuperado de http s://revistas.unal.edu.co/index.php/anpol/article/view/46017/47570

Theidon, K. (2015). Ocultos a plena luz: los niños nacidos de la violencia sexual en tiempos de guerra. Análisispolitico, 28 (85), 158-172. https://doi.org/10.15446/anpol.v28n85.56252

Torres, E., Cárdenas, Y. y Pertuz, C. (2018). La infancia y los niños en tiempos de guerra: el caso de Nicaragua, El Salvador y Guatemala. Palobra, 18, 194-215. https://doi.org/10.32997/2346-2884-vol.0-num.18-2018-2171

Tovar Rojas, P. (2006). Las viudas del conflicto armado en Colombia. Memorias y relatos. Bogotá: Instituto Colombiano de Antropología e Historia.

Truth and Reconciliation Commission of Canada. (2015). Honouring the truth, reconciling for the future: summary of the final report of the Truth and Reconciliation Commission of Canada. Recuperado de http://www.trc.ca/ websites/trcinstitution/File/2015/Honouring_the_Truth_Reconciling_for_the_Future_July_23_2015.pdf

Uceda, R. (2004). Muerte en el pentagonito. Los cementerios secretos del Ejército Peruano. Bogotá: Planeta.

Uribe Alarcón, M. V. (2015). Hilando fino. Voces femeninas en La violencia. Bogotá: Universidad del Rosario.

Uribe Alarcón, M.V. (2004). Antropología de la inhumanidad. Un ensayo interpretativo sobre el terror en Colombia. Bogotá: Editorial Norma.

Vallejo Franco, B. (2018). La construcción de la memoria histórica desde los niños, niñas y adolescentes en Colombia. En M. Bernal y A. Mendieta, (Eds.), Cátedra educación para la paz y la formación ciudadana (pp. 148-179). Bogotá: Universidad El Bosque.

Verdadabierta.com. (2017). ¿Qué pasó con los niños desaparecidos por los paras? Recuperado de https://verdadabie rta.com/los-ninos-desaparecidos-por-los-paras/

Vescovi, R. (1997). La mirada de los niños. Estudio sobre los hijos de los luchadores sociales en el Uruguay de los años duros. Boletin Americanista, 47, 233-248. Recuperado de https://revistes.ub.edu/index.php/BoletinAmericani sta/article/view/12991/16190

Vijeyarasa, R. (2007). Enfrentando la historia de Australia: verdad y reconciliación para las generaciones robadas. Sur. Revista Internacional de Derechos Humanos, 7(4), 29-153. Recuperado de https://www.scielo.br/scielo.php?pid $=$ S1806-64452007000200006\&script $=$ sci_abstract\&tlng=es

Villalta, C. (2009). De secuestros y adopciones: el circuito institucional de la apropiación criminal de niños en Argentina (1976-1983). Historia Crítica, 38, 146-171. Recuperado de https://doi.org/10.7440/histcrit38.200 9.08

Wang, D. (2004). Los niños escondidos. Del holocausto a Buenos Aires. Buenos Aires: Marea Editorial.

Winterberg, Y. y Winterberg, S. (2011). Los niños de la guerra. Los testimonios de la última generación de supervivientes de la Segunda Guerra Mundial. Barcelona: Aguilar.

Winterberg, Y. y Winterberg, S. (2015). Los niños en la primera guerra mundial. Bogotá: Editorial Planeta.

Zafra, E., Crego, R., y Heredia, C. (1989). Los niños españoles evacuados a la URSS (1937). Madrid: Ediciones de la Torre.

Zúñiga, M. (2010). Heridas en la memoria: la guerra civil salvadoreña en el recuerdo de niñez de un pandillero. Historia critica, 40, 60-83. https://doi.org/10.7440/histcrit40.2010.05 


\section{Notas}

1 Agradezco a la socióloga Anny Bertoli Varela por sus valiosos comentarios y recomendaciones que hicieron de este un mejor texto.

2 Vale aclarar que nos referimos a las comisiones de la verdad que derivan de procesos de justicia transicional tras la finalización de dictaduras, invasiones militares o conflictos armados, puesto que en los últimos años se han creado comisiones de la verdad en Estados unidos y Canadá -y propuesto la creación de otras en Oceanía- que específicamente indagan por la infancia indígena que fue raptada y privatizada en instituciones de protección para separarles de sus raíces y colonizarles con la idea de Estado-Nación (ICTJ, 2014; Truth and Reconciliation Commission of Canada, 2015; Vijeyarasa, 2007).

3 En América Latina la situación es parecida; son pocas las investigaciones que han incursionado en esta relación (Alcubierre y Carreño King, 1996; Casal, 2017; Castillo Gallardo, 2015; Castillo Gallardo y Gonzáles Celis, 2013, 2015 , 2019; Castillo Gallardo, Peña Fredes, Garrido, González Bertran, y Trujillo Arredondo, 2017; López Blanch, 2010; Llobet, 2015a, 2015b, 2016; Sosenski, 2012; Vescovi, 1997; Wang, 2004; Zuñiga, 2010).

4 De ese total 419.323 corresponden a niños entre 0-5 años, 852.881 a 6-11 años y 1.018.248 a 12-17 años (Gobierno de Colombia y Unidad para las Víctimas, 5 octubre 2018).

5 Para evitar generalizaciones, hay que hacer la salvedad que frente a esta tendencia son notables algunos casos en los que la representación hegemónica de la inocencia de los NNA impidió sus asesinatos en masacres perpetradas por paramilitares, diseñándose con ello otras infancias, determinadas por el rapto y el robo de su identidad en nuevas familias adoptivas decididas por los mismos paramilitares (Osuna, 2008). Igualmente, hubo masacres como la masacre de El Páramo cometida por las Autodefensas Campesinas del Casanare en la que a los NNA no se les asesinó (Herrera Durán, 2019), como igual ocurrió con la cometida contra Mario Calderón y Elsa Alvarado en la que los sicarios paramilitares no mataron a su hijo, un bebé por esa época (El Espectador, 2017).

6 Esta infancia es muy interesante por la conexión que tiene con la reproducción del conflicto armado. Por ejemplo, del secuestro de Zuleika, Yidid y Xioux, los hijos del narcotraficante José Jader Álvarez en 1981 por parte del M-19, se generó acto seguido un foco de paramilitarismo con la creación de Muerte a Secuestradores y el financiamiento de funcionarios del F2 de la policía nacional para encontrarlos y ajusticiar a los implicados (Hoyos, 2016). 